\title{
PÉ CAVO ADQUIRIDO NA DOENÇA DE CHARCOT-MARIE-TOOTH
}

ACQUIRED PES CAVUS IN CHARCOTMARIE-TOOTH DISEASE

Daniel Augusto Carvalho Maranho', José Batista Volpon²

\section{RESUMO}

As neuropatias sensitivomotoras hereditárias, principalmente a doença de Charcot-Marie-Tooth, manifestam-se frequentemente com o aparecimento de pé cavovaro, deformidade caracterizada pela acentuação fixa do arco plantar e inversão do retropé. O diagnóstico da doença de base e a cuidadosa avaliação do paciente fornecem os elementos-chave para decisão do tratamento. O cavo pode situar-se no antepé, retropé ou ser o resultado da associação das duas localizações. Deformidades combinadas, principalmente varismo e garras dos artelhos, devem ser bem avaliadas; as características clínicas como grau das alterações, acometimento da força muscular, flexibilidade e idade são fatores importantes para a decisão da conduta. $\mathrm{O}$ tratamento conservador do pé cavovaro por meio de fisioterapia, palmilhas e adaptação nos calçados é reservado ao paciente mais jovem ou casos levemente acometidos. Entretanto, há tendência de agravamento das deformidades devido à característica progressiva da doença neurológica de base. Assim, o tratamento cirúrgico pelas técnicas clássicas é indicado precocemente, sendo importante identificar as alterações primárias, diferenciá-las das secundárias e corrigi-las, se possível. As transferências musculares são usadas no sentido de minimizar o desequilíbrio, estruturas retraídas são seccionadas ou alongadas e osteotomias localizadas devem ser preferíveis às artrodeses, que são reservadas para pés rígidos e muito deformados de pacientes adultos.

Descritores - Polineuropatias; Doença de Charcot-Marie-Tooth; Deformidades do pé

\section{ABSTRACT}

Hereditary motor and sensory neuropathies, especially Charcot-Marie-Tooth disease, are frequently expressed with an acquired cavusvarus foot which is characterized by a fixed increase of the plantar arch and hindfoot inversion. Diagnosis of the underlying condition achieved through careful patient assessment and local evaluations is the keystone for decisionmaking about the adequate treatment. The cavus may present as an isolated deformity of the forefoot, hindfoot or it may be a combination of both locations. Related deformities, mainly the varus and toe clawing require appropriate evaluation; clinical characteristics such as severity of the deformity, impairment of the muscular power, flexibility and patient's age are important characteristics in the treatment decision. Conservative treatment of the cavusvarus foot with physiotherapy, insoles and shoe modifications are reserved to young patients and mild deformities. However, there is a tendency of the deformity to become more severe over time because of the progressive feature of the underlying neurological condition. So, the surgical treatment by using classical techniques is performed in early stages. Most importantly is the identification of the primary and main components of each deformity to properly correct them, if possible. Muscular transfers are used to treat the dynamic unbalance, retracted structures should be either divided or lengthened and localized osteotomies should be preferred over arthrodeses, which are reserved for stiff and severely deformed feet in adults.

Keywords - Polyneuropathies; Charcot-Marie-Tooth Disease; Foot deformities

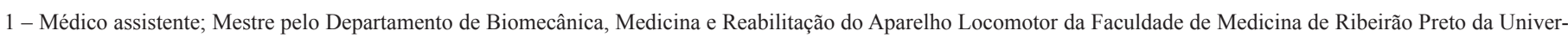
sidade de São Paulo.

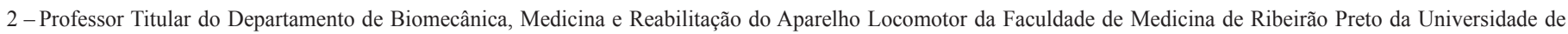
São Paulo.

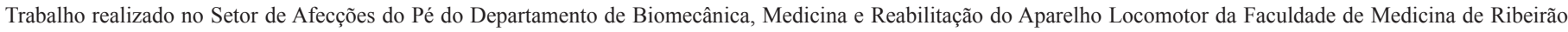
Preto da Universidade de São Paulo.

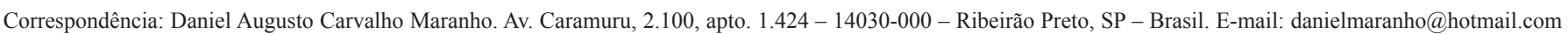
José B. Volpon. Rua São José, 655 - 14010-160 - Ribeirão Preto, SP - Brasil. E-mail: jbvolpon@fmrp.usp.br 


\section{INTRODUÇÃO}

O pé cavo é deformidade caracterizada pela acentuação fixa do arco plantar ${ }^{(1-3)}$; pode ser decorrente de alteração isolada localizada no antepé ou no retropé, ou ainda resultar da combinação das duas condições ${ }^{(4-6)}$. É um defeito complexo que pode associar-se a outras deformidades como o varismo, calcâneo, equino, adução e garras dos artelhos ${ }^{(3,7,8)}$. O termo mais comumente usado no meio ortopédico talvez seja "pé cavovaro" que, classicamente, se caracteriza pela flexão plantar do primeiro raio, pronação do antepé e varismo do retropé ${ }^{(9)}$.

O pé cavo adquirido é frequentemente causado por doença neurológica de base, sendo as neuropatias sensitivomotoras hereditárias as causas mais comuns ${ }^{(1,10,11)}$. Isso faz com que o tratamento desse pé na doença neuromuscular seja desafiador, porque a natureza progressiva do desequilíbrio muscular tende a causar recidivas, mesmo após correção cirúrgica adequada ${ }^{(11)}$.

\section{ETIOLOGIA}

Geralmente, o primeiro profissional a avaliar o paciente com pé cavo adquirido é o ortopedista, pois essa condição é incapacitante, causada por calosidades dolorosas, garras de artelhos e deformação dos calçados. Entretanto, o ortopedista deve considerar sempre que a etiologia mais provável da deformidade é uma doença neurológica de base, que deve ser investigada pelo neurologista ${ }^{(12)}$. Embora a condição mais comum da causa do pé cavo seja uma neuropatia sensitivomotora, principalmente a doença de Charcot-Marie-Tooth, outras afecções muito importantes devem ser consideradas, como tumores ou defeitos congênitos na medula espinhal (diastematomielia, seringomielia), etc.) ${ }^{(13)}$. Sinais clínicos de alerta para essas últimas condições são a progressão rápida, grande assimetria da deformidade, hiper-reflexia, clônus e alteração do controle dos esfíncteres $^{(1,14)}$. Entretanto, mesmo com investigação etiológica adequada, cerca de $30 \%$ dos casos são rotulados como idiopáticos ${ }^{(11,12)}$. Qualquer que seja a causa primária do pé cavo, o desequilíbrio muscular resultante é o denominador comum em todas elas.

\section{Neuropatias hereditárias sensitivomotoras}

As neuropatias hereditárias sensitivomotoras são um grupo heterogêneo de moléstias cujo conhecimento atual reflete a evolução de muitas outras áreas da neurociência ${ }^{(15)}$. Essa denominação não específi- ca foi proposta provisoriamente por Thomas et al ${ }^{(16)}$, mas adotada definitivamente nos anos seguintes por Dyck $^{(17)}$ que, a partir do conhecimento anatômico e fisiológico da época, elaborou uma classificação básica. Grande avanço surgiu com as técnicas de citogenética e biologia molecular, que possibilitaram a identificação de vários loci de genes, de tal forma que novos subtipos da doença continuam a ser descritos, resultando numa classificação bastante complexa, cujo interesse não é somente acadêmico, mas com a importância prática de informar sobre a evolução e realizar o aconselhamento genético ${ }^{(15)}$.

Entretanto, do ponto de vista ortopédico, ainda prevalece a classificação simplificada e clássica, que aceita o conceito amplo de neuropatias sensitivomotoras, basicamente representadas pela doença de CharcotMarie-Tooth.

\section{Doença de Charcot-Marie-Tooth (CMT)}

É afecção neurológica periférica progressiva, que causa hipotrofia muscular e deficiência da propriocepção ${ }^{(10)}$, tem o diagnóstico mais comumente associado ao pé cavo e deve ser suspeitada em todo paciente com essa deformidade. Consiste em manifestações clínicas mais ou menos típicas, com gravidade variável, decorrente de diversas anormalidades genéticas complexas que ocasionam defeitos nos nervos periféricos ${ }^{(18)}$.

Foi inicialmente descrita por Friedrich Schultze, em 1884. Recebeu os nomes do neurologista e professor de anatomia patológica, o francês Jean-Martin Charcot e seu aluno Pierre Marie, que descreveram a doença em 1886, e Howard Henry Tooth, que, independentemente, publicou a descrição da doença naquele mesmo ano, na Inglaterra. Charcot, Marie e Tooth relacionaram a doença com uma função anormal do sistema nervoso periférico apud Beals e Nickisch ${ }^{(18)}$ e Dyck et al ${ }^{(19)}$.

$\mathrm{Na}$ recente classificação neurogenética, o termo "neuropatia sensitivomotora" foi definitivamente substituído por Charcot-Marie-Tooth (CMT), que foi classificada em subtipos, de acordo com os achados clínicos, neuromioelétricos e citogenéticos.

A doença de CMT tipo 1 é a expressão mais comum (mais de 50\% dos casos), agrupa as formas desmielinizantes, apresenta herança autossômica dominante e baixa velocidade de condução nervosa (10 a 30m/s), porque a bainha de mielina é anormal ${ }^{(18)}$. É subdividida em CMT-1A, que é uma trissomia no cromossomo 17 , na região que contém o gene da proteína de mielina peri- 
férica 22 (PMP-22) e representa a maior parte dos casos (60 a 90\% das formas desmielinizantes). A CMT-1B corresponde à mutação no gene da proteína zero da mielina (P0) e o tipo CMT-1C, aos casos com defeitos não identificados. As formas CMT-1A e CMT-1B são as apresentações clínicas clássicas descritas originalmente por Charcot, Marie e Tooth ${ }^{(15,20,21)}$.

A doença de CMT tipo 2 (CMT-2) é a segunda forma mais comum e representa $20 \%$ dos casos, com neuropatia tipo axonal. Também é autossômica dominante, mas a velocidade de condução nervosa está quase normal, pois não há evidência de desmielinização e a amplitude do impulso é diminuída por causa do acometimento axonal $^{(18)}$. A doença de CMT-3 é historicamente importante (doença de Déjèrine-Sottas), de maior gravidade e, atualmente, a maior parte dos casos tem herança dominante. As formas recessivas, raras, foram classificadas como doença de CMT-4. A doença de CMT tipo X representa um conjunto de alterações ligadas ao cromossomo X; assim, homens são afetados, mas mulheres raramente o são ${ }^{(15,18,20)}$.

A doença de CMT produz desequilíbrio muscular distal, o que, nos membros inferiores, leva a deformidades nos pés bilateralmente, com leve assimetria em relação à força e às deformidades ${ }^{(18)}$. Não é a fraqueza absoluta de um músculo que produz as alterações, mas o desequilíbrio entre grupos musculares. Classicamente, produz enfraquecimento relativo dos músculos do compartimento lateral e anterior, mas o acometimento preferencial é dos músculos fibular curto e tibial anterior, em virtude da desnervação seletiva que neles ocorre. Com a progressão, a doença afeta também os compartimentos posteriores, causando hipotrofia de toda a musculatura da perna e pés ("perna de cegonha") (22-24).

As alterações sensitivas acontecem mais tardiamente na doença ${ }^{(22,23)}$, são frequentes e afetam as sensibilidades proprioceptiva, vibratória, dolorosa, tátil e térmica ${ }^{(25)}$. Nos membros superiores, a musculatura intrínseca da mão é a primeira a sofrer hipotrofia, de forma simétrica, seguida pela musculatura do antebraço. A doença poupa relativamente os músculos do ombro, tronco e face ${ }^{(22)}$. Os reflexos musculotendíneos estão diminuídos ou abolidos simetricamente ${ }^{(20)}$. Os sintomas são iniciados nas primeiras décadas de vida e evoluem lentamente, com progressão de distal para proximal. A intensidade de acometimento é variável de caso para caso e o prognóstico também, geralmente produzindo incapacidade leve ou moderada, mas,pode haver limitação importante ${ }^{(20)}$.

\section{ANATOMIA PATOLÓGICA DO PÉ CAVO}

Há grande variação anatômica no conjunto das deformidades que produzem o cavo, e que, didaticamente, podem ser analisadas individualmente. A deformidade pode ser leve, flexível e indolor, ou grave, rígida e incapacitante, com calosidades plantares e instabilidade lateral no tornozelo. Assim, o padrão de desequilíbrio muscular e o grau de acometimento das partes moles e ósseas devem ser isoladamente interpretados ${ }^{(1)}$. Enfim, não existe um padrão comum de alterações em todos os casos de pé cavo e tanto a avaliação quanto o tratamento devem ser individualizados ${ }^{(9,11)}$.

O cavo pode situar-se no antepé, no retropé ou em ambas as regiões ${ }^{(2,4,6)}$. A avaliação radiográfica do pé em perfil é útil para determinar a localização anatômica principal da deformidade ${ }^{(6)}$.

A gênese da maioria das deformidades está relacionada com o desequilíbrio das musculaturas intrínseca e extrínseca do pé, com padrões muito diversificados. Acredita-se que a fraqueza na doença de CMT tenha um componente importante na musculatura intrínseca do pé ${ }^{(23,26)}$, o que é apoiado pelo surgimento precoce de garras dos artelhos ${ }^{(27)}$; o processo de retração fibrótica dos músculos intrínsecos levaria à acentuação do arco longitudinal. Entretanto, há casos de cavo acentuado sem a ocorrência de garras ${ }^{(28)}$.

O padrão inicial de desequilíbrio comumente encontrado na doença de CMT é a fraqueza do músculo fibular curto, que não equilibra a força inversora do músculo tibial posterior, e a fraqueza do músculo tibial anterior, com relativa preservação da força do músculo fibular longo e tríceps sural ${ }^{(23,29-31)}$. Há preservação relativa da força do músculo extensor longo do hálux, que passa a agir com o dorsiflexor do tornozelo, quando o músculo tibial anterior está enfraquecido.

\section{Antepé}

A deformidade em cavo do antepé consiste na flexão plantar dos metatarsais, que é, em geral, mais acentuada na coluna medial, principalmente no primeiro raio ${ }^{(3,4)}$. O ponto crítico dessa alteração é que ela causa varismo secundário no retropé ${ }^{(32)}$.

O desequilíbrio muscular resulta da ação do músculo fibular longo não contrabalanceada pelo músculo tibial anterior, que está enfraquecido ${ }^{(4,23,30)}$. Assim, o músculo fibular longo flexiona plantarmente o primeiro metatarsal, causa a pronação do antepé e, consequentemente, produz o cavo. Entretanto, a coluna lateral permanece 
inalterada. Na descarga do peso, o pé como um todo é forçado em supinação para acomodar o equino do primeiro raio, o que leva o retropé em varo ${ }^{(32,33)}$.

Nos estágios iniciais da deformidade, apesar de as forças musculares manterem as deformidades, o pé é flexível, pois as partes moles ainda são elásticas e não há deformidades ósseas ou articulares associadas. Nessa circunstância, a articulação subtalar compensa a pronação do antepé e o varo não se desenvolve. Com a progressão da doença, estruturas flexíveis como a fáscia plantar, cápsulas articulares e ligamentos interósseos tornam-se contraturados e a deformidade estrutura-se $\mathrm{e}^{(3,32,34)}$.

A avaliação do cavo localizado no antepé na radiografia é feita no perfil com carga, onde o eixo longitudinal do tálus deixa de se continuar com o do primeiro metatarsal. A interrupção do eixo longitudinal ocorre no mediopé e o equino do primeiro metatarsal é, então, evidenciado.

A adução do antepé surge quando o músculo tibial posterior está ativo na presença de fraqueza do músculo fibular curto $^{(23)}$. A adução aumenta mais a pressão na coluna lateral do pé e pode surgir fratura por estresse na base do quinto metatarsal, além de piora das calosidades ${ }^{(35-38)}$.

\section{Retropé}

Embora a deformidade calcaneocavo possa ocorrer na doença de CMT, classicamente há deformidade equinocavo, pois o tríceps sural e o músculo tibial posterior sofrem hipotrofia mais tardiamente que o músculo tibial anterior $^{(11,22-24)}$. No entanto, outros autores relataram que o retropé está dorsiflexionado e não em flexão plantar, e, portanto, o cavo do antepé é o responsável pelo aspecto em equino do pé como um todo ${ }^{(39)}$.

O cavo, quando está localizado no retropé, surge em decorrência do desequilíbrio muscular resultante da fraqueza do músculo tríceps sural e relativa preservação da musculatura intrínseca ${ }^{(12)}$. Desse modo, há excesso de inclinação do calcâneo, com tendência à verticalização ${ }^{(23)} \mathrm{e}$ contratura das partes moles. Clinicamente, há piora do arco plantar, já aumentado, e a radiografia em perfil com carga caracteriza-se pelo aumento do ângulo calcâneo-solo (ângulo de pegada do calcâneo ou pitch), maior que $30^{\text {o(11) }}$.

No pé cavo o eixo da articulação subtalar está mais verticalizado e a cabeça do tálus tende a se situar sobre o processo anterior do calcâneo. Assim, há menor mobilidade da subtalar e as articulações tarsais transversas também estão mais rígidas ${ }^{(6)}$. O navicular não está posicionado medialmente ao cuboide, mas superiormente, o que restringe a mobilidade da articulação de Chopart e bloqueia o retropé em inversão ${ }^{(3)}$. Ocorre diminuição de absorção de impactos na marcha pela capacidade restrita de eversão do retropé durante a fase do médio apoio $^{(3,6,40)}$, com sobrecarrega da coluna lateral do pé ${ }^{(3)}$, podendo ocasionar fraturas por estresse ${ }^{(40)}$.

O varo é agravado pela tração do tendão do calcâneo e pela contratura da fáscia plantar, que se tornam mais medializados ${ }^{(3,28)}$; a maior tendência de apoio na borda lateral do pé exacerba a sintomatologia ${ }^{(7)}$. O cavo associado ao varo do retropé, contratura da fáscia plantar e fraqueza do músculo fibular curto provoca sobrecarga nos ligamentos laterais do tornozelo, o que, cronicamente, produz instabilidade em varo nessa articulação, com risco de artrose tibiotársica futura ${ }^{(3,23,41)}$. Além disso, acredita-se que a deformidade cavovaro possa provocar sobrecarga de pressão medialmente na articulação tibiotársica, mesmo quando o complexo ligamentar do tornozelo é competente ${ }^{(42)}$.

\section{Outros componentes}

A fáscia plantar atua fisiologicamente como um mecanismo de mola para absorver impactos, elevar o arco plantar, flexionar os metatarsais plantarmente e inverter o calcâneo. No pé cavo essa estrutura está contraturada ${ }^{(7)}$ e, como ela é anatomicamente mais espessa e forte na porção medial, sua retração não só mantém a acentuação do arco plantar, mas contribui para a adução do antepé e varização do calcâneo ${ }^{(6)}$. É também fonte de dor plantar medial (fasciite plantar) ${ }^{(3)}$.

As deformidades nos artelhos são variáveis quanto ao tipo, flexibilidade e gravidade. As garras e a hiperextensão das articulações metatarsofalangianas (MTF) restringem a capacidade de apoio de carga durante o desprendimento do pé e o poder de impulsão. Elas surgem a partir da fraqueza da musculatura intrínseca e relativa preservação da força dos extensores longos dos dedos, que hiperestendem as articulações MTF, e dos flexores longos dos dedos, que flexionam as articulações interfalangianas ${ }^{(23,31)}$.

Nos casos com flexão plantar mais acentuada dos metatarsais, o coxim plantar do antepé migra distalmente em relação às cabeças metatarsais, que ficam mais expostas à carga ${ }^{(1,9,43,44)}$. Além disso, a migração distal do coxim plantar diminui o apoio dos artelhos. A hiperextensão da MTF, com calosidade sob a cabeça metatarsal, e a flexão das interfalangianas, com calosidade dorsal, são fonte importante de dor e incapacidade ${ }^{(45)}$.

Os músculos extensor longo do hálux e dos dedos, que atuam como dorsiflexores auxiliares do tornozelo, não são contrabalanceados pelos músculos intrínsecos, enfraquecidos, e agravam a garra do hálux e demais artelhos ${ }^{(23)}$. 


\section{DIAGNÓSTICO}

O paciente típico é jovem, queixa-se de deformação progressiva dos pés com calosidades, dificuldade no uso de calçados e deformidades dolorosas nos artelhos ${ }^{(27)}$, geralmente com casos semelhantes na família. Ao se constatar pé cavo adquirido, há necessidade de exame pelo neurologista ${ }^{(11)}$, mas o ortopedista deve fazer avaliação preliminar da sensibilidade, atrofias e reflexos tendíneos. Não devem ser esquecidos os membros superiores e o equilíbrio, bem como a progressão das alterações, pois esses aspectos são importantes na decisão do tratamento.

O exame ortopédico é o convencional, mas com atenção para identificar as queixas principais, estabelecer o grau da deformidade e as alterações associadas. Uma boa avaliação das calosidades é essencial, pois elas são as causas de dor e espelham o distúrbio mecânico existente. A presença de calosidades sugere que a deformidade não seja mais flexível ${ }^{(44)}$. O exame da marcha deve analisar o contato do pé com o solo e, na fase de balanço, observar se há tendência ao "pé caído", bem como hiperextensão dos artelhos resultante da ação dos extensores longos que tentam compensar a fraqueza da dorsiflexão.

O teste de Coleman é realizado para estimar a influência do antepé no varismo do retropé e a flexibilidade da deformidade ${ }^{(32)}$. Pode ser realizado em três etapas, porém, a primeira e a segunda são as mais importantes. $\mathrm{O}$ teste consiste em retirar a carga da cabeça do primeiro metatarsal pelo apoio apenas do calcanhar e borda lateral do pé em uma tábua. Se há melhora nítida do varo, significa que a deformidade é redutível e secundária à inclinação excessiva do primeiro raio ${ }^{(32)}$. Quando todo o antepé está em equino, o apoio apenas do calcâneo na tábua fará desaparecer o varo (se a deformidade for flexível).

Instabilidade lateral no tornozelo é um achado comum, devido ao varismo do retropé associado à falência das forças estabilizadoras (fibular curto), que favorece a ocorrência de entorses ${ }^{(3,23,40,41)}$. A ocorrência de impacto anterior na tibiotársica deve também ser avaliada.

A investigação radiográfica deve incluir incidências axiais do calcâneo, frente e perfil dos pés, com carga. No perfil, a angulação entre o eixo longitudinal do primeiro metatarsal e do tálus (ângulo de Meary maior que $5^{\circ}$ ) indica que há cavismo no antepé. No cavo do retropé o calcâneo posiciona-se mais verticalizado, com aumento do ângulo calcâneo-solo (maior que $30^{\circ}$ ) e aumento do ângulo entre o eixo longitudinal do calcâneo e do primeiro metatarsal (ângulo de Hibbs maior que $\left.90^{\circ}\right)$. A altura do navicular está aumentada. Como, no pé cavovaro, a radiografia em perfil do pé gera uma visão oblíqua do tornozelo, há uma imagem artefatual onde a fíbula aparece posteriorizada e o dômus talar tem aspecto achatado $^{(3)}$.

A confirmação diagnóstica da afecção de base com exame neurológico completo, eletroneuromiografia, citogenética e outros exames de imagens é, em geral, realizada pelo neurologista.

\section{TRATAMENTO CONSERVADOR}

O tratamento conservador fica restrito aos casos iniciais com doença lentamente progressiva, em geral com pé ainda flexível, pouco doloroso, razoavelmente plantígrado, com boa força muscular, nos pacientes mais jovens. Consiste no uso de palmilhas, órteses, modificações nos calçados e fisioterapia ${ }^{(18)}$. Essa visa a manter a flexibilidade do pé com exercícios enfatizados no ganho de mobilidade global e alongamento das estruturas retraídas $^{(30)}$. Em geral, o tratamento conservador é feito de forma temporária ${ }^{(44)}$

Nas deformidades flexíveis, a palmilha deve ter revestimento macio, ser confeccionada sob molde, de modo que se adapte à planta do pé e faça alívio da carga nas regiões de pressão anômala, geralmente as cabeças dos metatarsais, e ter apoio retrocapital. $\mathrm{O}$ estudo da distribuição das cargas com a baropodometria pode ajudar nessa etapa ${ }^{(46)}$. Nos pés flexíveis com equino do primeiro raio, a elevação lateral no antepé pode ser benéfica para acomodar o metatarsal e prevenir a varização do retropé(11). Os calçados devem ser comuns, mas confortáveis e de caixa alta, para acomodar o pé e a palmilha. Órteses semirrígidas para alinhamento do retropé, inclusive com barras estabilizadoras laterais, podem ser prescritas nos casos mais graves e com instabilidade lateral no tornozelo ${ }^{(47)}$, mas são de pouca aceitação pelo desconforto e comprometimento estético que apresentam.

Foi sugerido que medidas conservadoras podem atrasar a progressão da deformidade ${ }^{(30)}$ ou até mesmo provocar sua regressão ${ }^{(28)}$. Também, já houve sugestão de que o tratamento cirúrgico pode ser postergado, pois a cirurgia nem sempre seria necessária e muitos pacientes poderiam ser tratados de forma conservadora ${ }^{(9)}$. Isso é verdadeiro, principalmente nos casos leves. Entretanto, muitos autores acreditam que o tratamento conservador do pé cavo, com o passar do tempo, não seja suficiente e que o atraso da correção cirúrgica apenas pioraria a 
deformidade $^{(6)}$, pois, no esqueleto imaturo, o desequilíbrio muscular pode levar a deformações ósseas ${ }^{(9,23)}$. Segundo esses autores, o ideal seria atuar precocemente na deformidade, enquanto ela é flexível, por meio de liberações, transferências tendíneas ou osteotomias localizadas ${ }^{(6,23,30,48,49)}$, que são procedimentos mais simples e menos agressivos ${ }^{(50)}$.

\section{TRATAMENTO CIRÚRGICO}

O objetivo do tratamento cirúrgico é obter um pé plantígrado, indolor, estável e, se possível, com flexibilidade e força muscular. É importante lembrar que, no pé cavo, uma deformidade pode ser secundária a outra e, se o pé for flexível, a correção da deformidade primária levará à correção da alteração secundária. $\mathrm{O}$ principal exemplo é o varo secundário do retropé, pois a correção do equino do primeiro raio corrigirá o varo, em pés flexíveis ${ }^{(32)}$. Se o retropé é rígido e persistir varismo no teste de Coleman, a osteotomia do calcâneo tipo Dwyer ${ }^{(7,28)}$ deve ser associada ${ }^{(9,33)}$.

Pés cavos flexíveis e sem deformidade óssea estabelecida devem ser tratados com procedimentos de partes moles, como fasciotomia plantar medial associada ou não a transferências tendíneas ${ }^{(6,34,49)}$, sendo as mais comuns a transferência do fibular longo para o curto e o procedimento de Jones. As transferências tendíneas são especialmente indicadas quando há desequilíbrio muscular com característica progressiva e são importantes para prevenir recidivas ${ }^{(44)}$.

Pés com deformidades osteoarticulares específicas, mas ainda flexíveis, além dos procedimentos de partes moles, devem ser submetidos a osteotomias, como elevação da extremidade distal do primeiro metatarsal, osteotomia do mediopé (Cole, Japas) ou do calcâneo (Dwyer, associada ou não ao deslizamento cranial do fragmento posterior). Como, geralmente, existem deformidades associadas, os procedimentos são combinados para a correção de cada componente primário da deformidade $^{(51)}$.

Opções cirúrgicas que preservam as articulações são sempre preferíveis, mas casos mais graves e rígidos devem ser submetidos à artrodese tríplice, que também é aplicada como procedimento de salvação em falhas cirúrgicas prévias ${ }^{(6,22,43,50,52-54)}$.

Casos com equino secundário à retração do músculo tríceps sural requerem especial avaliação da marcha e da força do quadríceps, pois alongar o tendão do músculo já enfraquecido e no membro com fraqueza do quadrí- ceps provocará piora da marcha. Essa situação deve ser tratada aceitando-se o equino do retropé e deixando o pé plantígrado por meio da artrodese tríplice pela clássica técnica de Lambrinudi ${ }^{(55)}$. Esse procedimento, herança das técnicas usadas nas sequelas de poliomielite, tem a vantagem de restabelecer um pé plantígrado, mantendo o equino do retropé, ou seja, sem enfraquecer mais o tríceps sural. Além disso, o equino que surge na extensão do joelho e desaparece com a sua flexão pode ser adequadamente tratado com o alongamento seletivo do gastrocnêmio $^{(31,47)}$. Já o alongamento do tendão de Aquiles no pé calcaneocavo constitui iatrogenia, pois piora a marcha em calcâneo ${ }^{(33)}$.

Garras leves e flexíveis dos artelhos frequentemente resolvem-se espontaneamente com a correção cirúrgica do cavo no mediopé( ${ }^{(28)}$. A necessidade de correção dessas deformidades leves pode ser pesquisada semiologicamente antes da cirurgia com a elevação passiva do antepé e verificando se elas desaparecem. Entretanto, a garra pode não se corrigir completamente ou ser uma deformidade primária e completamente rígida. Quando ela é reversível, a indicação é a transferência do tendão do músculo flexor longo dos dedos para os extensores dos dedos, de acordo com a técnica de GirdlestoneTaylor ${ }^{(56,57)}$. Se há hiperextensão fixa da articulação metatarsofalangiana, a indicação é realizar alongamento dos tendões extensores e capsulotomia ampla dessa articulação ${ }^{(1,45)}$. Se, após a capsulotomia e liberação tendínea, persistir a subluxação dorsal da falange, está indicada a osteotomia de Weil para encurtamento metatarsal $^{(9,58,59)}$. A deformidade fixa em flexão da articulação interfalangiana requer artrodese ou artroplastia de ressecção (DuVries) $)^{(1,45)}$.

A osteotomia de elevação da extremidade distal do primeiro metatarsal ${ }^{(60)}$ poucas vezes é feita como procedimento único, mas combinada com a fasciotomia plantar medial e mesmo com a osteotomia do calcâneo ${ }^{(1)}$. Uma técnica bem aceita consiste no acesso dorsal sobre a região proximal do osso, inserção de um parafuso perpendicularmente ao eixo longitudinal do primeiro metatarsal, ressecção de cunha de base dorsal deixando o córtex plantar íntegro para sofrer uma fratura em galho verde e o consequente fechamento da cunha. A correção é mantida por cerclagem transóssea ancorada distalmente no osso e proximalmente no parafuso ${ }^{(1)}$. Eventualmente, o segundo metatarsal também precisa ser corrigido. Em caso de esqueleto imaturo, não deve ser lesada a placa de crescimento do primeiro metatarsal, que fica na base do osso. 
A osteotomia do calcâneo pela técnica de Dwyer ${ }^{(7)}$ é procedimento clássico indicado na presença de varismo rígido do retropé. $\mathrm{O}$ acesso ao osso é feito através de uma incisão oblíqua retilínea lateral no calcanhar logo abaixo do tendão fibular longo, indo da região do extremo anterior e superior da tuberosidade posterior do calcâneo e terminando na junção inferior da tuberosidade posterior com o corpo do calcâneo. É retirada cunha de base lateral; o corte superior deve ser localizado imediatamente abaixo do tendão fibular longo. $\mathrm{O}$ córtex medial é preservado e servirá de fulcro no fechamento da osteotomia. A fixação pode ser feita com grampos, parafusos ou fios de Kirschner ${ }^{(1)}$.

Em casos de cavo do retropé com ângulo calcâneosolo elevado, está indicada a osteotomia de deslizamento cranial do fragmento inferior do calcâneo ${ }^{(61,62)}$, associada ou não à osteotomia de Dwyer (procedimento de Samilson modificado $)^{(1)}$. Entretanto, esse procedimento enfraquece o tríceps sural, o que pode diminuir a força de impulsão.

As osteotomias na região do mediopé são indicadas quando o cavo é consequência do equino de todo o antepé e não apenas dos raios mediais. A osteotomia de Cole $\mathrm{C}^{(30)}$ consiste na retirada de uma cunha de base dorsal no mediopé, mas tem o efeito indesejável de causar encurtamento ${ }^{(4)}$. A osteotomia de Japas ${ }^{(4)}$ corresponde a um corte em "V" no mediopé com correção do equino do antepé. A osteotomia cupuliforme de Akron tem um poder de correção multidirecional $^{(63)}$. Embora tenham a vantagem de atuar no ápice da deformidade, os cortes das osteotomias cruzam as articulações do mediopé e provocam artrodeses, o que pode não ser desejável. Há outras osteotomias nessa região, mas com localização mais distal ${ }^{(27,64)}$, o que representa menor capacidade de correção, além de poderem causar deformidade em "S". Giannini et al ${ }^{(65,66)}$ descreveram bons resultados com a associação de fasciotomia plantar, artrodese da articulação naviculocuneiforme e osteotomia do cuboide, em pés flexíveis.

\section{REFERÊNCIAS}

1. Guyton GP, Mann RA. Pes cavus. In: Coughlin MJ, Mann RA, Saltzman C. Surgery of the foot and ankle. Philadelphia: Mosby; 2007. p. 1125-48.

2. Barenfeld PA, Weseley MS, Shea JM. The congenital cavus foot. Clin Orthop Relat Res. 1971;(79):119-26.

3. Aminian A, Sangeorzan BJ. The anatomy of cavus foot deformity. Foot Ankle Clin. 2008;13(2):191-8

4. Japas LM. Surgical treatment of pes cavus by tarsal V-osteotomy. Preliminary report. J Bone Joint Surg Am. 1968;50(5):927-44.

5. Brockway A. Surgical correction of talipes cavus deformities. J Bone Joint Surg Am. 1940;22:81-91.
As artrodeses são reservadas para os casos mais graves, rígidos ou com artrose importante e sintomática, após a maturidade esquelética ${ }^{(1,6,9,11,22,43,50,52-54)}$. Têm a vantagem de associar estabilização à correção da deformidade e a desvantagem de gerar sobrecarga e artrose das articulações adjacentes ${ }^{(52-54)}$. Entretanto, quando há muito prejuízo da sensibilidade, principalmente a profunda, ela pode provocar, em longo prazo, degenerações articulares tipo junta de Charcot $^{(67,68)}$.

Finalmente, para pés muito deformados, geralmente já submetidos a cirurgias e com más condições de partes moles e de pele, há possibilidade de correção seguindo os princípios da técnica de Ilizarov ${ }^{(69,70)}$.

A recidiva da deformidade tem sido observada mesmo após a artrodese tríplice e é atribuída ao desequilíbrio muscular residual e à característica progressiva da doença ${ }^{(44,52,53,71)}$. O uso de órteses bem adaptadas e palmilhas no período pós-operatório é válido e tem como objetivos manter a correção e prevenir o aparecimento de lesões tegumentares neuropáticas ${ }^{(44)}$.

Um estudo recente relata baixa taxa de alterações degenerativas e de reoperações, em longo prazo, em pacientes com doença de CMT e pés cavovaros flexíveis submetidos à fasciotomia plantar, transferência do fibular longo para o curto e osteotomia de elevação do primeiro metatarsal. Foi comum a recidiva do varo e a ocorrência de um pequeno cavo residual, mas a maioria dos pés tinha bons índices funcionais ${ }^{(71)}$. No entanto, poucos estudos relacionados com os resultados pós-operatórios na cirurgia do pé cavovaro na doença de CMT foram publicados e, considerando o pequeno número de pacientes e a heterogeneidade da doença, não dispomos de evidências absolutas que estabeleçam um tratamento padrão-ouro ${ }^{(18)}$. A tendência atual no tratamento do pé cavovaro na doença de CMT é a intervenção precoce no pé e tornozelo com o objetivo atenuar o desequilíbrio muscular para diminuir a perda de função e a morbidade em longo prazo $^{(1,21)}$.

6. Samilson RL, Dillin W. Cavus, cavovarus, and calcaneocavus - an update. Clin Orthop Relat Res. 1983;(177):125-32.

7. Dwyer FC. Osteotomy of the calcaneum for pes cavus. J Bone Joint Surg Br. 1959;41(1):80-6.

8. Vlachou M, Beris A, Dimitriadis D. Modified Chuinard-Baskin procedure for managing mild-to-moderate cavus and claw foot deformity in children and adolescents. J Foot Ankle Surg. 2008;47(4):313-20.

9. Solis G, Hennessy M, Saxby T. Pes cavus: a review. Foot Ankle Surg. 2000;6:145-53.

10. Brewerton D, Sandifer $P$, Sweetnam D. "Idiopathic" pes cavus: an investigation into its aetiology. Br Med J. 1963;2(5358):659-61. 
11. Alexander IJ, Johnson KA. Assessment and management of pes cavus in Charcot-Marie-Tooth disease. Clin Orthop Relat Res. 1989;(246):273-81.

12. Bradley GW, Coleman SS. Treatment of the calcaneocavus foot deformity. J Bone Joint Surg Am. 1981;63(7):1159-66.

13. Schwend RM, Hennrikus W, Hall JE, Emans JB. Childhood scoliosis: clinical indications for magnetic resonance imaging. J Bone Joint Surg Am. 1995;77(1):46-53.

14. Bassett GS, Monforte-Munoz H, Mitchell WG, Rowland JM. Cavus deformity of the foot secondary to a neuromuscular choristoma (hamartoma) of the sciatic nerve. A case report. J Bone Joint Surg Am. 1997;79(9):1398-401.

15. Marques Junior W. Neuropatias hereditárias. Rev Bras Ortop Pedr 2002;3(2):58-66.

16. Thomas PK, Calne DB, Stewart G. Hereditary motor and sensory polyneuropathy (peroneal muscular atrophy). Ann Hum Genet. 1974;38(2):111-53.

17. Dyck PJ. Inherited neuronal degeneration and atrophy affecting peripheral motor, sensory and autonomic neurons. In: Dyck PJ, Thomas PK, Lambert EH. Peripheral neuropathy. Philadelphia: Saunders; 1975. p. 825.

18. Beals TC, Nickisch F. Charcot-Marie-Tooth disease and the cavovarus foot Foot Ankle Clin. 2008;13(2):259-74

19. Dyck PJ, Chance P, Lebo R, Carney JA. Hereditary motor and sensory neurophaties. In: Dyck PJ, Thomas PK. Peripheral neuropathy. Philadelphia: Saunders; 1993. p. 1094-136

20. Pareyson D. Differential diagnosis of Charcot-Marie-Tooth disease and related neuropathies. Neurol Sci. 2004;25(2):72-82.

21. Burns J, Ryan MM, Ouvrier RA. Evolution of foot and ankle manifestations in children with CMT1A. Muscle Nerve. 2009;39(2):158-66.

22. Jacobs JE, Carr CR. Progressive muscular atrophy of the peroneal type (Charcot-Marie-Tooth disease). Orthopaedic management and end-result study. J Bone Joint Surg Am. 1950;32(1):27-47.

23. Mann RA, Missirian J. Pathophysiology of Charcot-Marie-Tooth disease. Clin Orthop Relat Res. 1988;(234):221-8.

24. Sabir M, Lyttle D. Pathogenesis of Charcot-Marie-Tooth disease. Gait analysis and electrophysiologic, genetic, histopathologic, and enzyme studies in a kinship. Clin Orthop Relat Res. 1984;(184):223-35.

25. Harding AE, Thomas PK. The clinical features of hereditary motor and sensory neuropathy types I and II. Brain. 1980;103(2):259-80.

26. Price AE, Maisel R, Drennan JC. Computed tomographic analysis of pes cavus. J Pediatr Orthop. 1993;13(5):646-53.

27. Swanson AB, Browne HS, Coleman JD. Cavus foot - concepts of production and treatment by metatarsal osteotomy. J Bone Joint Surg Am. 1966;48(5):1019.

28. Dwyer FC. The present status of the problem of pes cavus. Clin Orthop Relat Res. 1975;(106):254-75.

29. Helliwell TR, Tynan M, Hayward M, Klenerman L, Whitehouse G, Edwards RHT. The pathology of the lower leg muscles in pure forefoot pes cavus. Acta Neuropathol. 1995;89(6):552-9.

30. Cole WH. The treatment of claw-foot. J Bone Joint Surg Am. 1940;22:895-908.

31. Marks RM. Midfoot and forefoot issues cavovarus foot: assessment and treatment issues. Foot Ankle Clin. 2008;13(2):229-41.

32. Coleman SS, Chesnut WJ. Simple test for hindfoot flexibility in cavovarus foot Clin Orthop Relat Res. 1977;(123):60-2.

33. Paulos L, Coleman SS, Samuelson KM. Pes cavovarus - review of a surgical approach using selective soft-tissue procedures. J Bone Joint Surg Am 1980;62(6):942-53.

34. Schwend R, Drennan J. Cavus foot deformity in children. J Am Acad Orthop Surg. 2003;11(3):201-11.

35. Sabir M, Lyttle D. Pathogenesis of pes cavus in Charcot-Marie-Tooth disease Clin Orthop Relat Res. 1983;(175):173-8.

36. Holmes JR, Hansen ST Jr. Foot and ankle manifestations of Charcot-MarieTooth disease. Foot Ankle. 1993;14(8):476-86

37. Theodorou DJ, Theodorou SJ, Boutin RD, Chung C, Fliszar E, Kakitsubata $Y$, et al. Stress fractures of the lateral metatarsal bones in metatarsus adductus foot deformity: a previously unrecognized association. Skeletal Radiol. 1999;28(12):679-84

38. Younger A, Hansen SJ. Adult cavovarus foot. J Am Acad Orthop Surg 2005;13(5):302-15.

39. Aktas S, Sussman MD. The radiological analysis of pes cavus deformity in Charcot Marie Tooth disease. J Pediatr Orthop B. 2000;9(2):137-40.

40. Chilvers $M$, Manoli A, 2nd. The subtle cavus foot and association with ankle instability and lateral foot overload. Foot Ankle Clin. 2008;13(2):315-24.
41. Fortin PT, Guettler J, Manoli A 2nd. Idiopathic cavovarus and lateral ankle instability: recognition and treatment implications relating to ankle arthritis. Foot Ankle Int. 2002;23(11):1031-7.

42. Krause F, Windolf $M$, Schwieger K, Weber M. Ankle joint pressure in pes cavovarus. J Bone Joint Surg Br. 2007;89(12):1660-5.

43. Brewster AH, Larson CB. Cavus feet. J Bone Joint Surg Am. 1940;22:361-8.

44. Lee MC, Sucato DJ. Pediatric issues with cavovarus foot deformities. Foot Ankle Clin. 2008;13(2):199-219.

45. Coughlin MJ. Lesser-toe abnormalities. J Bone Joint Surg Am. 2002;84(8):1446-69

46. Crosbie J, Burns J, Ouvrier RA. Pressure characteristics in painful pes cavus feet resulting from Charcot-Marie-Tooth disease. Gait Posture. 2008;28(4):545-51.

47. Krause FG, Wing KJ, Younger AS. Neuromuscular issues in cavovarus foot. Foot Ankle Clin. 2008;13(2):243-58.

48. Gould N. Surgery in advanced Charcot-Marie-Tooth disease. Foot Ankle. 1984;4(5):267-73.

49. Roper BA, Tibrewal SB. Soft tissue surgery in Charcot-Marie-Tooth disease. J Bone Joint Surg Br. 1989;71(1):17-20.

50. Levitt RL, Canale ST, Cooke AJ, Gartland JJ. Role of foot surgery in progressive neuromuscular disorders in children. J Bone Joint Surg Am. 1973;55(7):1396-410.

51. Dekel S, Weissman SL. Osteotomy of the calcaneus and concomitant plantar stripping in children with talipes cavo-varus. J Bone Joint Surg Br. 1973;55(4):802-8

52. Wetmore RS, Drennan JC. Long-term results of triple arthrodesis in CharcotMarie-Tooth disease. J Bone Joint Surg Am. 1989;71(3):417-22.

53. Wukich DK, Bowen JR. A long-term study of triple arthrodesis for correction of pes cavovarus in Charcot-Marie-Tooth disease. J Pediatr Orthop. 1989;9(4):433-7

54. Mann DC, Hsu JD. Triple arthrodesis in the treatment of fixed cavovarus deformity in adolescent patients with Charcot-Marie-Tooth disease. Foot Ankle. 1992;13(1):1-6.

55. Hart VL. Lambrinudi operation for drop-foot. J Bone Joint Surg Am. 1940;22:937-41.

56. Taylor RG. The treatment of claw toes by multiple transfers of flexor into extensor tendons. J Bone Joint Surg Br. 1951;33(4):539-42.

57. Pyper JB. The flexor-extensor transplant operation for claw toes. J Bone Joint Surg Br. 1958;40(3):528-33.

58. Barouk LS. Weil's metatarsal osteotomy in the treatment of metatarsalgia Orthopäde. 1996;25(4):338-44.

59. Trnka HJ, Gebhard C, Muhlbauer M, Ivanic G, Ritschl P. The Weil osteotomy for treatment of dislocated lesser metatarsophalangeal joints: good outcome in 21 patients with 42 osteotomies. Acta Orthop Scand. 2002;73(2):190-4.

60. McElvenny RT, Caldwell GD. A new operation for correction of cavus foot; fusion of first metatarsocuneiformnavicular joints. Clin Orthop. 1958;11:85-92.

61. Mitchell GP. Posterior displacement osteotomy of calcaneus. J Bone Joint Surg Br. 1977;59(2):233-5

62. Samilson RL. Crescentic osteotomy of the os calcis for calcaneocavus feet. In: Bateman JE. Foot Science. Philadelphia: Saunders; 1976. p. 18-25.

63. Weiner DS, Morscher M, Junko JT, Jacoby J, Weiner B. The Akron dome midfoot osteotomy as a salvage procedure for the treatment of rigid pes cavus: a retrospective review. J Pediatr Orthop. 2008;28(1):68-80.

64. Jahss $\mathrm{MH}$. Tarsometatarsal truncated-wedge arthrodesis for pes cavus and equinovarus deformity of the fore part of the foot. J Bone Joint Surg Am. 1980;62(5):713-22

65. Giannini S, Ceccarelli F, Benedetti MG, Faldini C, Grandi G. Surgical treatment of adult idiopathic cavus foot with plantar fasciotomy, naviculocuneiform arthrodesis, and cuboid osteotomy. A review of thirty-nine cases. J Bone Joint Surg Am. 2002;84(Suppl 2):62-9.

66. Amiot R, Coulter T, Nute M, Wilson S, Amiot R. Surgical treatment of adult idiopathic Cavus Foot. J Bone Joint Surg Am. 2003;85(7):1400-1.

67. Pell RFt, Myerson MS, Schon LC. Clinical outcome after primary triple arthrodesis. J Bone Joint Surg Am. 2000;82(1):47-57.

68. Zwipp H, Rammelt S, Dahlen C, Reichmann H. The Charcot joint. Orthopäde 1999;28(6):550-8.

69. Kucukkaya M, Kabukcuoglu Y, Kuzgun U. Management of the neuromuscula foot deformities with the llizarov method. Foot Ankle Int. 2002;23(2):135-41.

70. Catagni MA, Guerreschi F, Manzotti A, Knuth A. Treatment of foot deformities using the Ilizarov method. Foot Ankle Surg. 2000;6(4):207-37.

71. Ward CM, Dolan LA, Bennett DL, Morcuende JA, Cooper RR. Long-term results of reconstruction for treatment of a flexible cavovarus foot in Charcot-MarieTooth disease. J Bone Joint Surg Am. 2008;90(12):2631-42. 